\title{
Complexes of Iron(II) with Cysteine-Containing Peptides in the Gas Phase
}

\author{
Olga V. Nemirovskiy and Michael L. Gross \\ Department of Chemistry, Washington University, St. Louis, Missouri
}

\begin{abstract}
Gas-phase interactions of peptides that contain cysteine with iron(II) atoms were examined by using fast-atom bombardment and tandem mass spectrometry. Specific and strong interactions of iron and sulfur from the thiol group of the cysteine side chain occur in the gas phase and are the basis for highly specific fragmentation to give abundant $\left[\mathrm{a}_{n}-2 \mathrm{H}+\mathrm{Fe}\right]^{+}$ ions. For peptides that contain two cysteines, an internal ion, which results from the interaction of $\mathrm{Fe}$ and both thiol groups, is formed upon collisional activation. The mechanism for the formation of $\left[\mathrm{a}_{n}-2 \mathrm{H}+\mathrm{Fe}\right]^{+}$fragment ions requires the metal to be coordinated at sulfur in close proximity to the site of reaction. Iron-bis(pentapeptide) complexes, which form under the same conditions, decompose predominantly to lose a pentapeptide molecule and, to a lesser extent, to give $\left[\mathrm{a}_{n}-2 \mathrm{H}+\mathrm{Fe}\right]^{+}$ions. (J Am Soc Mass Spectrom 1996, 7 , 977-980)
\end{abstract}

$\mathrm{M}$ otivations to study metal-peptide complexes in the gas phase are to understand intrinsic binding of peptides and metal ions and to develop new approaches to structure determination of peptides [1-14]. Most recent efforts in this emerging mass-spectrometric area are directed at the nature of interactions of small peptides and alkali [1-5], alkaline-earth [8-10], and transition metals [11-14].

When cationized by alkali metals, peptides undergo a predominant rearrangement reaction and produce $\left[b_{n}+\mathrm{Cat}+\mathrm{OH}\right]^{+}$ions $[1,6,7]$. The most abundant fragment obtained upon collisional activation (CA) reveals the identity of the $C$-terminal amino acid. Significant structural information also can be obtained from the investigation of peptides cationized by alkaline-earth metal ions [8-11]. Positively charged species $[8,10]$ such as [peptide $-\mathrm{H}+\mathrm{Cat}{ }^{+}$decompose to form a and c-ions, which indicate that the predominate binding sites involve either amide or side-chain groups. Negatively charged complexes that involve divalent metal ions [9] [peptide $-3 \mathrm{H}+\mathrm{Cat}^{-}$ display a much stronger interaction, and fragment upon collisional activation to give a series of $x, y$, and $z$ ions.

Transition metals offer the most diverse and interesting chemistry by formation of a variety of complexes with peptides [11-18]. Unlike the alkali and alkaline-earth metals, where the bonding is predominantly electrostatic in origin, the coordination com-

Address reprint requests to Professor M. L. Gross, Department of Chemistry, Washington University, One Brookings Drive, Campus Box 1134, St. Louis, MO 63130. plexes of transition metals with peptides should exhibit binding with a substantial degree of covalence.

Metal ion-peptide bonding in the gas phase may involve not only peptide linkages, but also side chains. Examples of the latter are the interactions of alkali-metal ions with a basic site of the side chain, the bonding of $\mathrm{Zn}, \mathrm{Co}, \mathrm{Ni}[13,17,18]$, and $\mathrm{Cu}[18]$ with the imidazole nitrogen of the His side chain, the bonding of transition metal ions with the aromatic ring of Tyr or Phe [14], and the interaction of alkaline-earth metal ions with the $-\mathrm{OH}$ group of peptides that contain the protic amino acids Asp, Glu, and Tyr [10]. Because metal ion-binding sites on the side chains of peptides play an important role in the biochemistry, further study of the intrinsic interactions in the gas phase is of interest.

The interaction of $\mathrm{Fe}$ ions and sulfides is common in all forms of life, and these groups are found at the active centers of a wide variety of redox and catalytic proteins, such as ferrodoxins, rubredoxins, and metalloenzymes. In most ferrodoxins and in all rubredoxins the protein ligands are cysteines, which provide thiolate donors to the $\mathrm{Fe}$ center $[15,16,19,20]$. On the basis of evidence that the iron atoms are usually held in the proteins by cysteine ligands, we decided to examine the interactions of $\mathrm{Fe}(\mathrm{II})$ and sulfur-containing peptides and to test whether iron can be used as an "indicator" of the location of the cysteine residues in peptides. The strategy is to desorb Fe(II) complexes of cysteine-containing peptides by fast-atom bombardment (FAB) and cause them to undergo collisionally activated decompositions (CAD). In this article, we show data that this strategy works well for a series of pentapeptides that contains Cys at various positions. 


\section{Results and Discussion}

Upon FAB desorption, complexes were introduced into the gas phase as [peptide $-\mathrm{H}+\mathrm{Fe}]^{+}$complexes. The abundances of these ions are comparable to those of protonated species formed under the same conditions. To form these monopositive complexes, one proton is removed and replaced with the metal ion. The likely proton-donor sites are the carboxyl group of the Cterminal amino acid, the amide groups of the peptide bonds, and the thiol group of the Cys side chain. The first two groups are classified as hard ligands, whereas the thiol group is considered soft. According to the hard-soft-acid-base theory [21, 22], hard metal ions prefer to bind to hard ligands, whereas soft metal ions will form the most stable complexes by binding to soft ligands. $\mathrm{Fe}(\mathrm{II})$ is a borderline acid, and it can bind to both hard and soft ligands. Binding to soft ligands, however, will result in a greater degree of covalence and lead to more stable complexes. Therefore, we expect that the thiol group of the cysteine side chain will be the primary proton donor. This expectation is also supported by experimental data: (1) the loss of a $\mathrm{H}_{2} \mathrm{O}$ molecule requires the presence of a free $\mathrm{OH}$ group at the C-terminus and (2) binding to the various amide nitrogens should lead to a more complicated CAD spectra than is observed (see Figure 1).

\section{Formation of $\left[\mathrm{a}_{n}-2 \mathrm{H}+\mathrm{Fe}\right]^{+}$Ions}

The position of the Cys residue in the pentapeptideiron complexes strongly influences the fragmentation when the complexes are subjected to collisional activation in a tandem mass spectrometer. Specific interactions of the iron atoms with the thiol group of the Cys side chain are the basis for highly specific fragmentation to give abundant $\left[\mathrm{a}_{n}-2 \mathrm{H}+\mathrm{Fe}\right]^{+}$ions, where $n$ is the position of the Cys residue with respect to the $\mathrm{N}$-terminus of the peptide backbone (see Figure 1).

The first three peptides, VGACL, VGCAL, and VCGAL, whose CAD spectra are shown in Figure 1 are isomeric and contain only one cysteine residue. The fourth peptide (Figure 1d) contains two cysteines, located one amino acid apart. The CAD spectra of the first three peptide-iron complexes are very simple and are dominated by two ions, one of which is formed by loss of water to give the product of $m / z$ 498; the others are the $\left[a_{n}-2 \mathrm{H}+\mathrm{Fe}\right]^{+}$ions (of $m / z 357,286$, and 229 as seen in Figure 1a, b, and c, respectively).

The loss of $\mathrm{H}_{2} \mathrm{O}$ is facile because all peptides studied here contain a free C-terminal amino acid. The proposed mechanism for the loss of 18 from the precursor ions is similar to that reported by Teesch and Adams [8], and proceeds through the formation of four-membered rings and involves $\alpha$-hydrogen transfer. Other possible sources of the hydrogen, such as the $\beta$-position of the C-terminal amino acid side chain or the amide group, are not considered because they lead to losses of $\mathrm{CO}_{2}$ and $\mathrm{H}_{2} \mathrm{CO}_{2}\left(\mathrm{H}_{2} \mathrm{O}\right.$ and $\left.\mathrm{CO}\right)$ [11], which

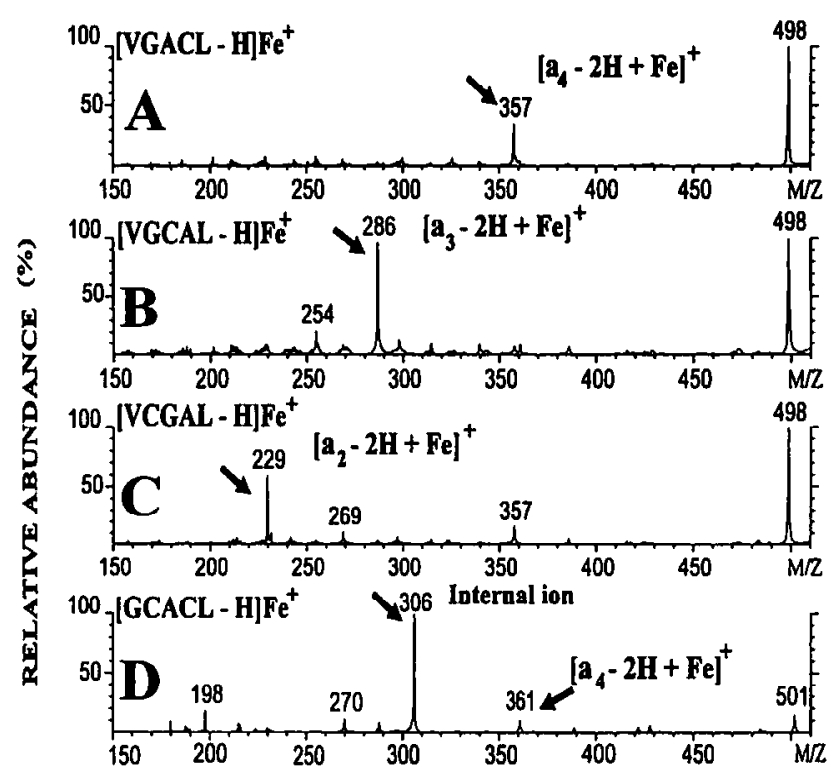

Figure 1. The CAD spectra of cysteine-containing pentapeptides, desorbed as $[\mathrm{M}-\mathrm{H}+\mathrm{Fe}]^{+}$complexes of (A) VGACL, (B) VGCAL, (C) VCGAL ( $m / z 516)$, and (D) GCACL ( $m / z$ 519).

are not observed. According to the mechanism, iron ions bond to the peptide near to the $\mathrm{N}$-terminus, leaving the C-terminal carboxylate free of the metal.

The formation of $\left[\mathrm{a}_{n}-2 \mathrm{H}+\mathrm{Fe}\right]^{+}$ions may proceed by two mechanisms that differ in the source of the transferred hydrogen. One mechanism involves amide-hydrogen transfer (Scheme I), whereas the other includes a rearrangement of a $\beta$-hydrogen. Isotope labeling experiments show that the only detectable hydrogen transferred is an amide hydrogen. Replacing all active hydrogens by deuterium, we observed that the iron(II) complex of VGCAL- $d_{8}$ decomposes to an $a_{3}$ type ion of $m / z$ 289. A similar mechanism was reported by Hu et al. [14] for the formation of $\left[\mathrm{a}_{n}-\mathrm{H}\right]^{+}$ ions from the transition metal-peptide complexes that contained Phe and Tyr residues. The mechanism in Scheme I is facilitated because the $\mathrm{N}-\mathrm{H}$ bond is weakened (the acidity of the $\mathrm{NH}$ is increased) as a result of coordination of the amide to the Fe center.

Formation of abundant $\left[\mathrm{a}_{n}-2 \mathrm{H}+\mathrm{Fe}\right]^{+}$fragment ions upon collisional activation does not rule out alternative binding of $\mathrm{Fe}(\mathrm{II})$ to the peptides. Other less abundant fragment ions, such as of $m / z 254$ for VGCAL, 269, 257 for VCGAL, and 198 and 270 for GCACL,
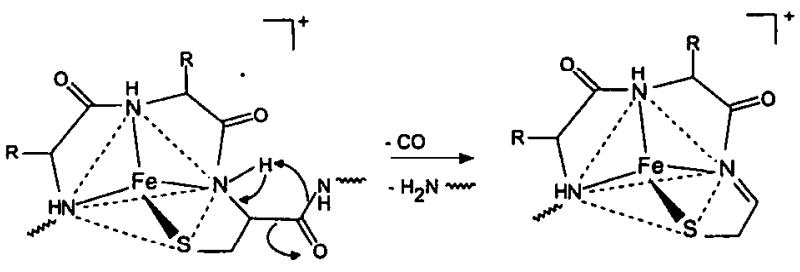

$\left(a_{n}-2 H+F e\right)^{+}$

Scheme I 
may indicate that the precursor ions are heterogeneous in structure.

\section{Formation of an Internal Ion}

For the pentapeptide that contains two Cys residues (Figure 1d), the metal ion primarily binds at these residues and at the amide nitrogens located between them (Scheme II) to form a structure that gives an internal ion of $m / z$ 306. Furthermore, the collisional activation of GCACL gives the expected, although less abundant, $\left[\mathrm{a}_{4}-2 \mathrm{H}+\mathrm{Fe}\right]^{+}$ion of $m / z 361$, whereas formation of $\left[\mathrm{a}_{2}-2 \mathrm{H}+\mathrm{Fe}\right]^{+}$ions of $m / z 286$ is suppressed. The strong interaction between $\mathrm{Fe}$ and both sulfurs directs the fragmentation to the periphery of both cysteines. The structure of the internal ion is similar to those in redox proteins where there are tetrahedral sites that contain one Fe and one S [15].

\section{Decomposition of Iron-Bis(Pentapeptide) Complexes}

Gas-phase iron-bis(pentapeptide) complexes also form upon FAB ionization. When submitted to collisional activation (CA), these bis complexes decompose predominantly by losing one pentapeptide to form an iron-bound pentapeptide (note the ion of $\mathrm{m} / z 516$ in Figure 2). Iron oxidation also accompanies the loss of a peptide radical [peptide $+\mathrm{H}^{\cdot}$ ] that leads to the formation of iron(III)-bound-pentapeptide complexes of the composition $[\mathrm{M}-2 \mathrm{H}+\mathrm{Fe}(\mathrm{III})]^{+}$of $m / z$ 515. Oneelectron oxidation of iron(II) is common for $\mathrm{Fe}-\mathrm{S}$-containing redox proteins, such as ferrodoxins and rubredoxins [15]. In addition, abundant ions (of $\mathrm{m} / z 548$ and 484) of $32 \mathrm{u}$ higher and lower than the mass of the $\mathrm{Fe}$-pentapeptide are formed, and they are likely to be [peptide $-\mathrm{H}+\mathrm{Fe}+\mathrm{S}]^{+}$and [peptide $-\mathrm{H}+\mathrm{Fe}-$ $\mathrm{S}^{+}$ions. The mechanism for the formation of these ions may involve an oxidation of two thiol groups to give an $-\mathrm{S}-\mathrm{S}-$ bond. For one ion, the disulfide bond is retained in the iron-bound-bis(pentapeptide) complex, whereas for the other ion it is lost as a part of the neutral (Scheme III).

The $\left[\mathrm{a}_{n}-2 \mathrm{H}+\mathrm{Fe}\right]^{+}$ions also form from bis(pentapeptide) complexes. Their precursor is likely to be the first-generation iron-bound peptide fragment that is formed from the bis(pentapeptide) complex. Other atype sequence ions that arise from either the $\mathrm{m} / \mathrm{z} 548$ or 484 precursor ions also are formed upon collisional

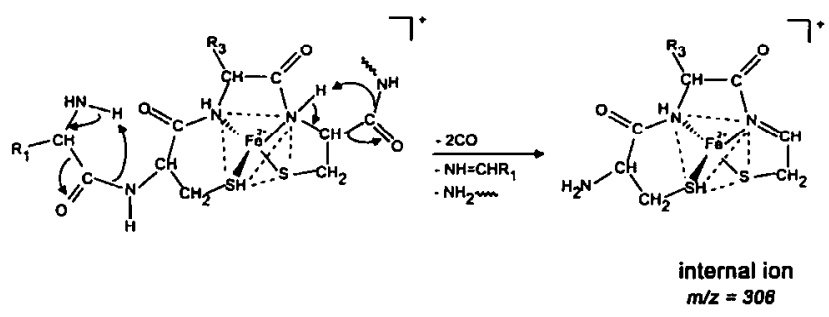

Scheme II

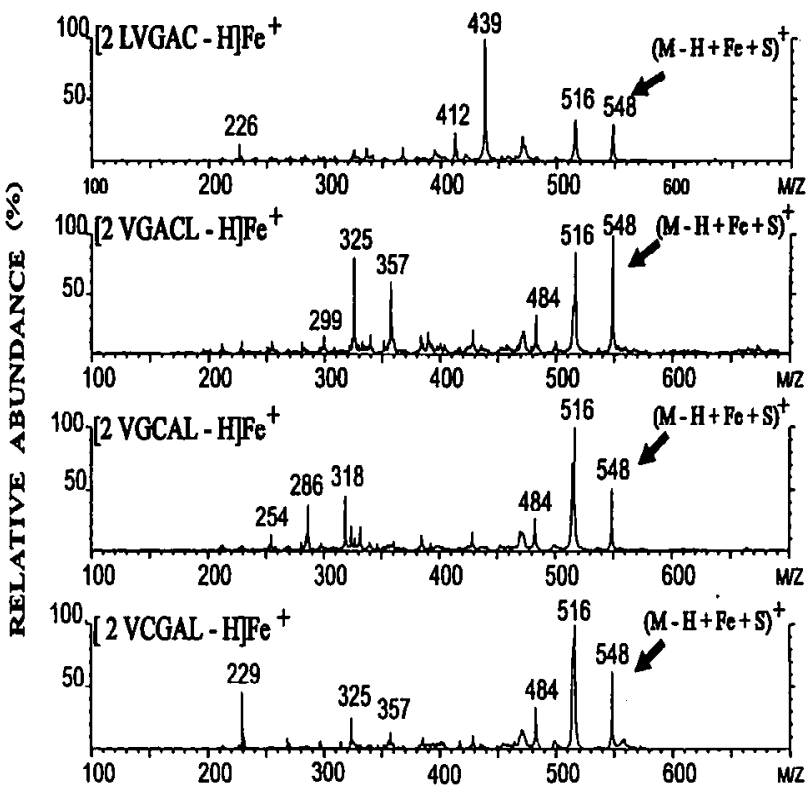

Figure 2. The CAD spectra of iron-bis(pentapeptide) complexes desorbed as $[2 \mathrm{M}-\mathrm{H}+\mathrm{Fe}]^{+}(m / z$ 977).

activation. For the iron-bound-bis(VGCAL) complex, both ions (i.e., those of $m / z 318$ and 254) that are 32 units different from the corresponding $\left[\mathrm{a}_{n}-2 \mathrm{H}+\right.$ $\mathrm{Fe}]^{+}$ion are present. Decomposition of the ironbound-bis(VGACL) complex gives only the $\left[\mathrm{a}_{4}-\right.$ $2 \mathrm{H}+\mathrm{Fe}-\mathrm{S}]^{+}$fragment ion and no $\left[\mathrm{a}_{2}-2 \mathrm{H}+\mathrm{Fe}+\right.$ $\mathrm{S}^{+}$or $\left[\mathrm{a}_{2}-2 \mathrm{H}+\mathrm{Fe}-\mathrm{S}\right]^{+}$ions.

In summary, specific and strong interaction of iron(II) with the thiol group of Cys-containing peptides, along with chelation to amide and amine nitrogens, occurs in the formation of metal-ion cationized peptides in the gas phase. These strong interactions lead to the formation of complexes that principally fragment to give the $\left[\mathrm{a}_{n}-2 \mathrm{H}+\mathrm{Fe}\right]^{+}$ions that form at

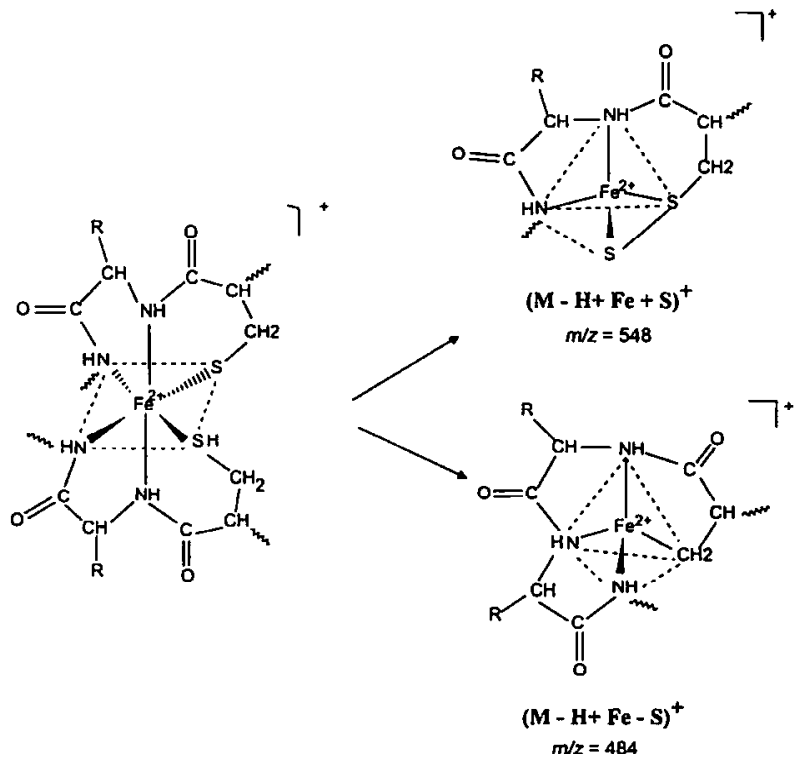

Scheme III 
the sites of the cysteine residue. The product ions themselves are likely to be stable because the Fe-S interaction is preserved in the fragmentation.

These results provide encouragement for further investigation of Fe-S interactions in peptides and for development of a method to locate cysteines and possibly disulfide bonds in small proteins and in peptide fragments in digests. Future work will include investigation of larger peptides with different number of Cys residues to determine the most stable coordination geometry of the iron-peptide complexes in the gas phase. Different transition metals also will be studied to test the specificity and generality of the interaction.

\section{Experimental}

The peptides used in this work were synthesized manually by stepwise solid-phase peptide synthesis from Fmoc-protected amino acids. The crude peptides were purified by reverse phase high performance liquid chromatography by using a C-18 column, and the collected fractions were lyophilized. The identity of the peptides was confirmed by FAB mass spectrometry and tandem mass spectrometry of the $[\mathrm{M}+\mathrm{H}]^{+}$ions. The matrix that was used to produce metal-peptide complexes was a 1:1 mixture of glycerol and thioglycerol saturated by $\mathrm{e}\left(\mathrm{NO}_{3}\right)_{2}$. The reagents for the matrix were obtained from (Sigma Chemical Co., St. Louis, MO).

Mass spectrometric experiments were performed on a VG ZAB-T (VG Analytical Ltd., Manchester, UK) four-sector instrument, which consisted of two high mass, double-focusing mass spectrometers of BEBE design. The instrument was equipped with a $\mathrm{Cs}^{+}$gun operated at $30 \mathrm{kV}$. The accelerating voltage for all experiments was $8 \mathrm{kV}$. FAB mass spectra were acquired by MS-1 at a mass resolving power of approximately 1500 (10\% valley depth). The second stage, which was a reverse-geometry, Mattauch-Herzog-type instrument with a planar electrostatic analyzer, was used to obtain the tandem mass spectra after the precursor ions were selected with MS-1 and activated with collisions with helium gas at pressures sufficient to give $50 \%$ main beam suppression. The fragment ions formed in the third field-free region were detected by an array detector. The collision cell was at $4 \mathrm{kV}$.

Data acquisition was carried out with a VG OPUS V 3.1X data system and interfaced to the mass spectrometer by a VG SIOS I unit.

To acquire both mass spectra and CAD spectra, $1 \mu \mathrm{L}$ of the matrix was mixed with $1 \mu \mathrm{L}$ of $1-\mu \mathrm{g} / \mu \mathrm{L}$ peptide solution. The probe was then exposed to the $22-\mathrm{kV} \mathrm{Cs}^{+}$beam to cause desorption. Usually, 10-20 scans were acquired and signal averaged.
Experiments with deuterium-labeled peptides were carried out by using $\mathrm{D}_{2} \mathrm{O}$ (Sigma Chemical Co.) as a solvent, which was added to the mixture of the peptide and iron-containing matrix on the FAB probe. The vacuum interlock of the $F A B$ source was used to pump away the volatile species $\mathrm{H}_{2} \mathrm{O}, \mathrm{HDO}$, and $\mathrm{D}_{2} \mathrm{O}$. To obtain nearly complete exchange, the procedure was repeated three times.

\section{Acknowledgment}

This work was supported by the National Institutes of Health (Resource Grant No. 2P41RR00954). We wish to thank the University of Nebraska Protein Facility for help with the peptide synthesis.

\section{References}

1. Tang, X.; Ens, W.; Standing, K. G.; Westmore, J. B. Anal. Chem. 1988, 60, 1791-1799.

2. Russell, D. H.; McGlohon, E. S.; Mallis, L. M. Anal. Chem. $1988,60,1818-1824$.

3. Grese, R. P.; Cerny, R. L.; Gross, M. L. J. Am. Chem. Soc. 1989, $111,2835-2842$.

4. Grese, R. P.; Gross, M. L. I. Am. Chem. Soc. 1990, 112, 5098-5104.

5. Leary, J. A.; Zhou, Z. R.; Odgen, S. A.; Williams, T, D. I. Am. Soc. Mass Spectrom. 1990, 1, 473-480.

6. Teesch, L. M.; Adams, J. J. Am. Chem. Soc. 1991, 113, 812-820.

7. Teesch, L. M.; Orlando, R. C.; Adams, J. J. Am. Chem. Soc. 1991, 113, 3668-3675.

8. Teesch, L. M.; Adams, J. I. Am. Chem. Soc. 1990, 112, $4110-4120$.

9. Hu, P.; Gross, M. L. J. Am. Chem. Soc. 1992, 114, 9153-9160.

10. Zhao, H.; Reiter, A.; Teesch, L. M.; Adams, J. J. Am. Chem. Soc. 1993, 115, 2854-2863.

11. Hu, P.; Gross, M. L. J. Am. Chem. Soc. 1993, 115, 8821-8828.

12. Galtin, C. L.; Turecek, F.; Vaisar, T. I. Am. Chem. Soc. 1995, 117, 3637-3638.

13. Loo, J. A.; Hu, P.; Smith, R. D. J. Am. Soc. Mass Spectrom. 1994, 5, 959-965.

14. Hu, P., Sorensen, C.; Gross, M. L. J. Am. Soc. Mass Spectrom. $1995,6,1079-1085$.

15. Bertini, I.; Gray, H. B.; Lippard, S. J.; Valentine, J. S. Bioorganic Chemistry, Univ. Science Books, Mill Valley, CA, 1994, pp. 365-421.

16. Patillot, Y.; Golinelli, M.; Forest, E.; Meyer, J. Biochem. Biophys. Res. Commun. 1995, 210, 686-694.

17. Sullards, C. M.; Adams, J. J. Am. Soc. Mass Spectrom. 1995, 6 , 608-610.

18. Hu, P.; Loo. J. A. J. Am. Chem. Soc. 1995, 117, 11314-11319.

19. Khrapova, N.; Malenkova, I.; Vanin, A. Biofizikn 1995, 40, 117-121.

20. Allen, M. H.; Hutchens, W. T. Rapid Commun. Mass Spectrom. 1992, 6, 308-312.

21. Cowan, J. A. Inorganic Biochemistry: An Introduction; VCH Publishers: New York, 1993; pp 7-8.

22. Pettit, L. D.; Gregor, J. E.; Kozlowski, H. In Perspectives on Bioinorganic Chemistry 1991, 1, 1-35. 